\title{
Thiamine and dystonia 16
}

\author{
Antonio Costantini, ${ }^{1}$ Erika Trevi, ${ }^{2}$ Maria Immacolata Pala, ${ }^{1}$ Roberto Fancellu ${ }^{3}$
}

${ }^{1}$ Department of Neurology, Villa Immacolata, Viterbo, Italy ${ }^{2}$ Department of Neurological Rehabilitation, Villa Immacolata, Viterbo, Italy ${ }^{3}$ Unit of Neurology, IRCCS San Martino University Hospital, Genoa, Italy

\section{Correspondence to} Dr Antonio Costantini, carapetata@libero.it

Accepted 8 July 2016
CrossMark

\footnotetext{
To cite: Costantini $A$, Trevi E, Pala MI, et al. BMJ Case Rep Published online: [please include Day Month Year] doi:10.1136/bcr-2016216721
}

\section{SUMMARY}

Primary torsion dystonia is a movement disorder characterised by sustained or intermittent involuntary muscle contractions causing abnormal movements, postures or both. In this study, 3 brothers affected by inherited primary dystonia 16 (DYT16) began an oral therapy with high-dose thiamine from November to December 2015. After 3 months, an important improvement of the motor symptoms was observed. Our results support the hypothesis that pathogenesis of the symptoms might be related to a dysfunction in mitochondrial oxidative phosphorylation due to a focal impairment of thiamine-dependent processes. Our results support some authors' hypothesis that dystonia might have a mitochondrial aetiology.

\section{BACKGROUND}

Primary torsion dystonia (PTD) is characterised by sustained muscle contractions, frequently causing repetitive twisting movements or abnormal postures. In PTD, dystonia is the only clinical sign, and there is no identifiable exogenous cause or other inherited or degenerative disease. ${ }^{1}$

Primary forms of dystonia are caused by neuronal dysfunction but not neuronal death. The result of the pathogenic changes in primary dystonia is a defect in neural networks involving the basal ganglia, sensorimotor cortex and cerebellum. Neuroimaging studies have enabled identification of structural and functional abnormalities in focal and generalised PTD. ${ }^{2}$

At present, only symptomatic therapy is possible. An effective therapy targeted at the pathogenic mechanism of dystonia is not yet available. ${ }^{1}$

PTD includes some genetic forms and forms for which a cause is no yet found.

Dystonia 16 (DYT16) is a rare form of inherited primary dystonia, characterised by early onset (infancy, childhood) progressive dystonia. The disease presents one of two possible phenotypes: either generalised dystonia or dystonia parkinsonism. Dystonia starts at one limb and later it progresses to other body regions. ${ }^{3}$

DYT16 is inherited in an autosomal recessive manner and is caused by a mutation in the protein kinase interferon-inducible double-stranded RNA-dependent activator (PRKRA) gene, located on chromosome $2 \mathrm{q} 31.2$. There is little information about the function of the encoded protein.

Defects in mitochondrial oxidative phosphorylation (OXPHOS) have been involved in a variety of neurodegenerative diseases. One neurological symptom which has definitely been associated with OXPHOS is the movement disorder dystonia. In fact, some authors hypothesised the intriguing possibility that dystonia might have a mitochondrial aetiology. ${ }^{4}$

In previous studies, we also formulated the hypothesis that, in some inherited or sporadic degenerative diseases and other disorders of the nervous system, the pathogenesis of the symptoms could be linked to a focal thiamine deficiency (TD) due to structural enzymatic abnormalities. ${ }^{5}$

We thought that this dysfunction could be responsive to high-dose thiamine. We treated with high-dose thiamine some patients suffering from sporadic PTD with good results too (personal data not yet published).

The classical syndrome caused primarily by TD in humans is beriberi and Wernicke-Korsakoff syndrome. ${ }^{6}$ Thiamine plays a key role in the maintenance of brain function. Thiamine-dependent processes are critical in glucose metabolism, and recent studies implicate thiamine in oxidative stress, protein processing, peroxisomal function and gene expression. ${ }^{\text {? }}$

Magnesium is a cofactor to transketolase and its administration to patients with TD being treated with thiamine demonstrated a positive effect on erythrocyte transketolase activity. Six decreased activities of thiamine-dependent enzymes have also been reported in neurodegenerative disease independent of patient malnutrition. ${ }^{8}$

Therefore, we have decided to treat the three brothers affected by DYT16 with high-dose thiamine, in order to clarify the potential thiamine effect in the treatment of the disease.

We requested a written consent to begin a thiamine-based therapy, in order to use the results for a publication. Some video recordings are attached to this study.

\section{CASE PRESENTATION}

Formerly, the three patients had been several times hospitalised at the University Departments of Neurological Sciences for a diagnostic specification. All the performed laboratory tests and nuclear magnetic resonance (NMR) brain results were normal. The brothers were given a diagnosis of familiar generalised dystonia. Subsequently, in October 2015 the three patients' parents and a sister, object, of this study, were found at the molecular analysis by direct sequencing, heterozygous carriers of the mutation c $665>T$ (p.Pro222Leu) in the gene PRKRA. The three brothers affected by dystonia presented the same mutation in homozygous character. The genetic test was performed at the molecular genetics laboratory of Ferrara University. ${ }^{9}$

The patients were affected by primary dystonia DYT16. The diagnosis of dystonia was based on clinical history, physical examination and genetic tests. ${ }^{1}$ 
We assessed the patients with dystonia according to the Fahn-Marsden Rating Scales (dystonia movement and disability scales).

Dystonia movement scale (DMS): this consists of provoking factors (scored 0-4) and severity factors (scored 0-4). Some are given a weight (W) of $1 / 2$, and others a W of 1 . All three are multiplied to give the adjusted score; all scores are summed to give an overall score (S) from 0 to $120 .^{10}$

Dystonia disability scale (DDS): a scale assessing the disability provoked by dystonia in seven items, whose six are scored 0-4 and the last $0-6$ (the gait assessment must consider the possible use of a wheelchair). The total score ranges from 0 to 30 .

As the patients did not want to start an intramuscular therapy, we used $500 \mathrm{mg}$ thiamine and $100 \mathrm{mg}$ magnesium (oxide, succinate, citrate, malate) tablets. The patients began an oral therapy with the two tablets, one each in the morning and at lunch time ( $2000 \mathrm{mg}$ of thiamine daily $+400 \mathrm{mg}$ dimagnesium) right after the evaluation of symptoms and history of the disease (November-December 2015).

\section{Patient 1}

Patient 1 was a 44-year-old male. He started to show the first signs of dystonia at the age of 8 years with slurred speech. After $\sim 2$ years, gait disturbance and bradicinesia also appeared which got worse very slowly.

Neurological examination: slight bradicinesia, generalised dystonia with prevalent torticollis and swallowing disturbance.

DMS at baseline: 50 points DDS: 33 points.

Thiamine plasmatic level: $38 \mu \mathrm{g} / \mathrm{L}$ (normal value (n.v) 28-85).

\section{Patient 2}

Patient 2 was a 39 -year-old male. Since the age of 4 years he has presented slurred speech of a pharyngeal-laryngeal kind of dystonia. At the age of 16 , the dystonic symptoms appeared at the neck, the chin and the other parts of the body.

Neurological examination: dystonic movements were found in all body regions, particularly the gait, the mouth and the limbs.

DMS 80 points DDS 15 points.

Thiamine plasmatic level: $45 \mu \mathrm{g} / \mathrm{L}$ (n.v. 28-85).

(Video 1: Patient 2 before 1).

(Video 2: Patient 2 before 2).

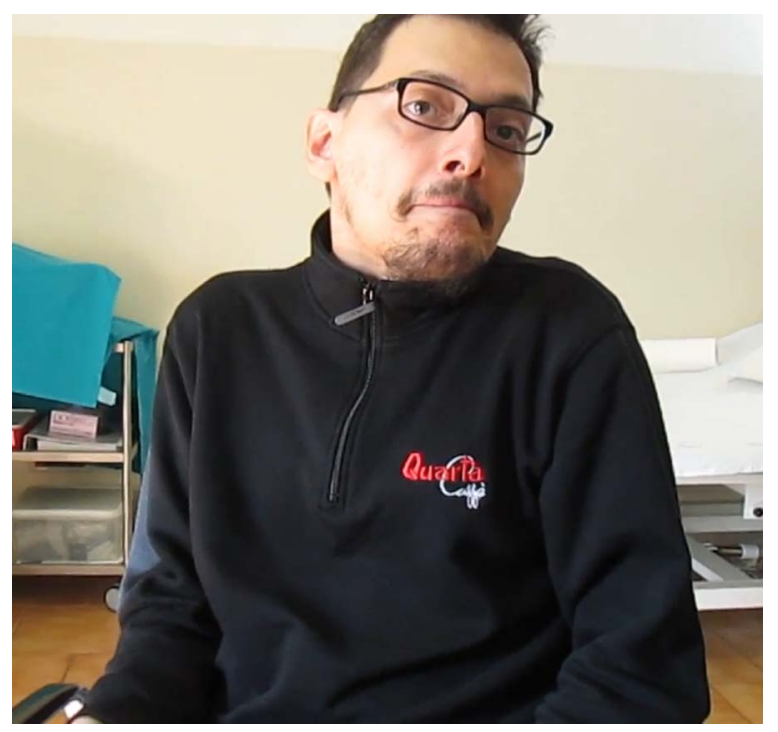

Video 1 Patient 2 before the therapy (1).

\section{Patient 3}

Patient 3 was a 36-year-old male. The first dystonic symptoms appeared at the age of 3 years at the upper limbs and the trunk. Later the disturbances progressed to the other body regions, especially to the trunk and the limbs.

Neurological examination: generalised dystonia with prevalent gait and handwriting disturbance (the patient could not hold a pen with his hand), bradicinesia.

DMS: 69 points DDS 14 points.

Thiamine plasmatic level: $67 \mu \mathrm{g} / \mathrm{L}$ (n.v. 28-85).

The patients were re-evaluated with neurological examination and Fahn-Marsden dystonia scales after 90 days of treatment (table 1).

\section{OUTCOME AND FOLLOW-UP}

After 90 days from the beginning of the therapy, we examined the patients and repeated the same tests.

The patients noticed a partial improvement of the symptoms as summarised below:

Pz 1 DMS 33 p. (improvement 40\%) DDS: 6 p. (improvement 40\%)

$\mathrm{He}$ had a nearly total regression of the swallowing disturbances.

Pz 2 DMS 61 p (improvement 23.7\%) DDS: 10 p (improvement $33.3 \%$ )

He had a global improvement of all dystonic movements (video 3: patient 2 after therapy).

Pz 3 DMS 49 p. (improvement 28.9\%) DDS: 10 p (improvement $28.6 \%$ )

He succeeds in writing, even if with some difficulties, and he walks much better (table 1).

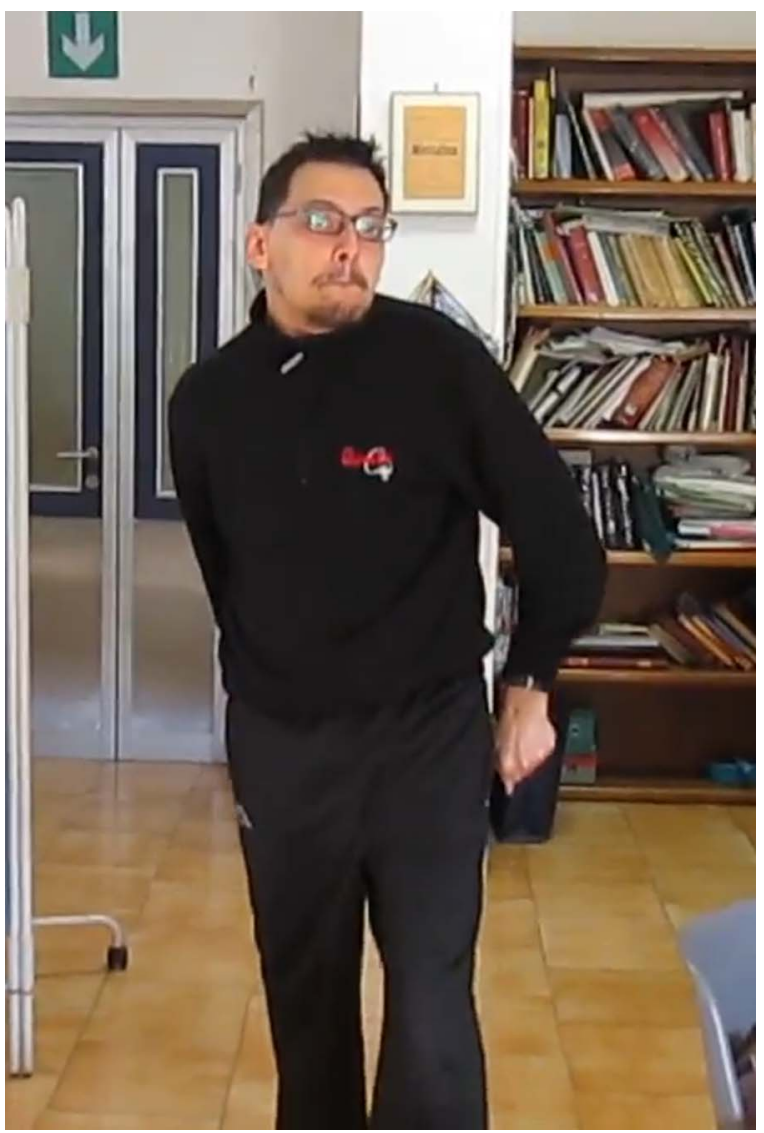

Video 2 Patient 2 before the therapy (2). 
Table 1 The Fahn-Marsden dystonia scales

\begin{tabular}{|c|c|c|c|c|c|c|c|c|c|c|c|c|c|c|c|c|c|c|c|}
\hline \multirow{2}{*}{\multicolumn{2}{|c|}{$\begin{array}{l}\text { Movement scale } \\
\text { Provoking factors (PF }\end{array}$}} & \multicolumn{3}{|c|}{ Patient 1 before } & \multicolumn{3}{|c|}{ Patient 1 after } & \multicolumn{3}{|c|}{ Patient 2 before } & \multicolumn{3}{|c|}{ Patient 2 after } & \multicolumn{3}{|c|}{ Patient 3 before } & \multicolumn{3}{|c|}{ Patient 3 after } \\
\hline & & & & & & & & & & & & & & & & & & & \\
\hline \multicolumn{2}{|c|}{ General } & 4 & & & 4 & & & 4 & & & 4 & & & 4 & & & 4 & & \\
\hline \multicolumn{2}{|c|}{$\begin{array}{l}\text { Speech and } \\
\text { swallowing } \\
\text { (SS) }\end{array}$} & 4 & & & 3 & & & 4 & & & 3 & & & 3 & & & 3 & & \\
\hline \multicolumn{20}{|c|}{ Severity factors (SF) } \\
\hline \multicolumn{2}{|c|}{ Eyes } & 0 & & & 0 & & & 3 & & & 1 & & & 0 & & & 0 & & \\
\hline \multicolumn{2}{|l|}{ Mouth } & 1 & & & 0 & & & 3 & & & 2 & & & 1 & & & 0 & & \\
\hline \multicolumn{2}{|l|}{ SS } & 2 & & & 1 & & & 2 & & & 1 & & & 1 & & & 1 & & \\
\hline \multicolumn{2}{|l|}{ Neck } & 2 & & & 1 & & & 2 & & & 2 & & & 2 & & & 1 & & \\
\hline \multicolumn{2}{|l|}{ Arm } & 2 & & & 1 & & & 3 & & & 3 & & & 3 & & & 2 & & \\
\hline \multicolumn{2}{|l|}{ Trunk } & 1 & & & 1 & & & 3 & & & 2 & & & 3 & & & 3 & & \\
\hline \multicolumn{2}{|l|}{ Leg } & \multicolumn{3}{|l|}{2} & \multicolumn{3}{|l|}{2} & \multicolumn{3}{|l|}{2} & \multicolumn{3}{|l|}{2} & \multicolumn{3}{|l|}{3} & \multicolumn{3}{|l|}{2} \\
\hline Scoring & W & $\mathrm{PF}$ & SF & Score & PF & SF & Score & PF & SF & Score & PF & SF & Score & PF & SF & Score & $\mathrm{PF}$ & SF & Score \\
\hline Eyes & 0.5 & 4 & 0 & 0 & 4 & 0 & 0 & 4 & 3 & 6 & 4 & 1 & 2 & 4 & 0 & 0 & 4 & 0 & 0 \\
\hline Mouth & 0.5 & 4 & 1 & 2 & 4 & 0 & 0 & 4 & 3 & 6 & 4 & 2 & 4 & 4 & 1 & 2 & 4 & 0 & 0 \\
\hline SS & 1.0 & 4 & 2 & 8 & 3 & 1 & 3 & 4 & 3 & 12 & 3 & 1 & 3 & 3 & 1 & 3 & 3 & 1 & 3 \\
\hline Neck & 0.5 & 4 & 2 & 4 & 4 & 1 & 2 & 4 & 2 & 4 & 4 & 2 & 4 & 4 & 2 & 4 & 4 & 1 & 2 \\
\hline Right arm & 1.0 & 4 & 2 & 8 & 4 & 1 & 4 & 4 & 3 & 12 & 4 & 3 & 12 & 4 & 3 & 12 & 4 & 2 & 8 \\
\hline Left arm & 1.0 & 4 & 2 & 8 & 4 & 1 & 4 & 4 & 3 & 12 & 4 & 3 & 12 & 4 & 3 & 12 & 4 & 2 & 8 \\
\hline Trunk & 1.0 & 4 & 1 & 4 & 4 & 1 & 4 & 4 & 3 & 12 & 4 & 2 & 8 & 4 & 3 & 12 & 4 & 3 & 12 \\
\hline Right leg & 1.0 & 4 & 2 & 8 & 4 & 2 & 8 & 4 & 2 & 8 & 4 & 2 & 8 & 4 & 3 & 12 & 4 & 2 & 8 \\
\hline Left leg & 1.0 & 4 & 2 & 8 & 4 & 2 & 8 & 4 & 2 & 8 & 4 & 2 & 8 & 4 & 3 & 12 & 4 & 2 & 8 \\
\hline Total (S) & & & & 50 & & & 33 & & & 80 & & & 61 & 69 & & & 49 & & \\
\hline Dystonia dis & bility & & & & & & & & & & & & & & & & & & \\
\hline Speech & & 2 & & & 1 & & & 2 & & & 1 & & & 1 & & & 1 & & \\
\hline Handwriti & & 1 & & & 1 & & & 3 & & & 2 & & & 4 & & & 3 & & \\
\hline Feeding & & 1 & & & 1 & & & 2 & & & 2 & & & 2 & & & 2 & & \\
\hline $\begin{array}{l}\text { Eating/ } \\
\text { swallowin }\end{array}$ & & 2 & & & 1 & & & 1 & & & 0 & & & 1 & & & 0 & & \\
\hline Hygiene & & 1 & & & 0 & & & 1 & & & 1 & & & 1 & & & 1 & & \\
\hline Dressing & & 1 & & & 0 & & & 3 & & & 2 & & & 2 & & & 1 & & \\
\hline Walking & & 2 & & & 2 & & & 3 & & & 2 & & & 3 & & & 2 & & \\
\hline Total & & 10 & & & 6 & & & 15 & & & 10 & & & 14 & & & 10 & & \\
\hline
\end{tabular}

\section{DISCUSSION}

The patients had a favourable response to thiamine. The oral therapy with high-dose thiamine was effective in reversing the motor failure, suggesting that the abnormalities in thiaminedependent processes could be overcome by a diffusion-mediated transport at supranormal thiamine concentrations. The presence of symptoms due to a TD in patients with normal concentrations of plasmatic thiamine could be explained if referred to defects of intracellular thiamine transport, activation and the attachment of the active cofactor to target enzymes. ${ }^{11}$

Furthermore, in the presence of TD the response to therapy is considered diagnostic. ${ }^{12}$

Thiamine responsive deficiency has been reported in other inborn errors of metabolism that lead to neurological diseases. ${ }^{13}$ Genetic disorders of thiamine metabolism that lead to neurological disease can be treated with high-dose thiamine. ${ }^{13-15}$ Recently, some authors achieved good results in sporadic degenerative diseases too (Parkinson's disease) with the same treatment. $^{5}$

The exact mechanism of thiamine responsiveness in these patients is unknown.
This clinical observation led us to presume that the symptoms featuring dystonia could have derived from a focal TD that determines a selective neuronal dysfunction. In other words, TD could have an important role in the pathogenesis of the disease's symptoms. Oral administration of large quantities of vitamin B1 increases the intracellular passive transport of thiamine and the symptoms decrease when glucose metabolism and other thiamine-dependent processes return to physiological levels.

The patients reported a general improvement of the voluntary motility. As we write this report, they continued the same therapy and maintained the same motor conditions, without any side effect. We believe that the therapy may play an important role in limiting the progression of the disease and we deem necessary a lifelong use of high-dose thiamine in affected individuals. Finally, also aetiologically-different dystonias could be responsive to high-dose thiamine. ${ }^{16}$

In the literature, there is no mention of thiamine-related adverse effects even at high doses and for very long-term lapses. ${ }^{9} 17$

In conclusion, we believe that this report represents an important contribution to the subject; nonetheless further research is necessary to confirm the present observation. 


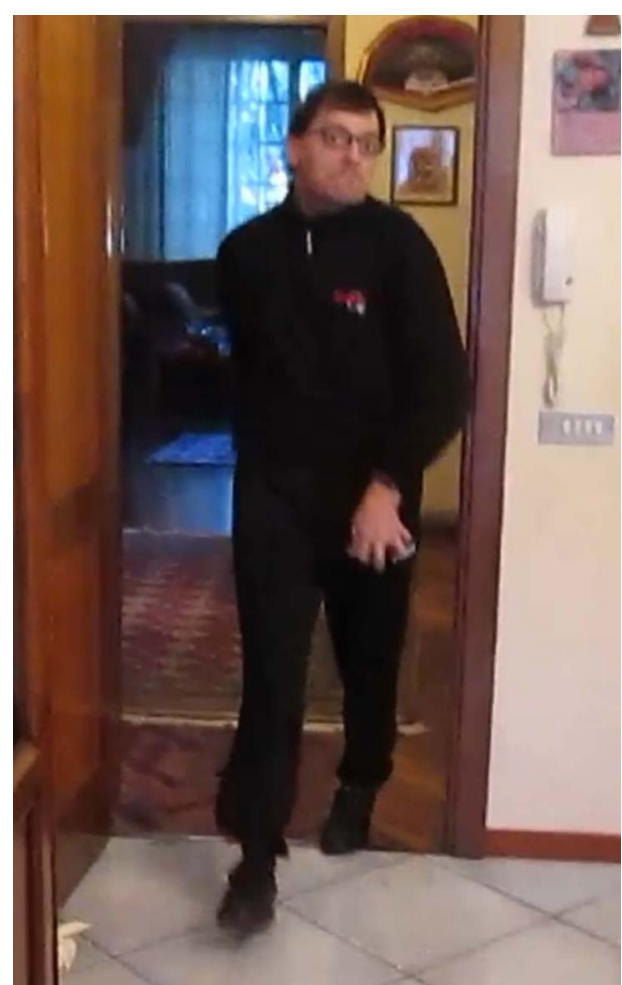

Video 3 Patient 2 after the therapy.

\section{Learning points}

- The treatment described in this paper is immediately available for the care of dystonia 16.

- In the literature there is no study that has observed side effects linked to the daily use of high doses of thiamine.

- We believe that this report opens a ray of hope for therapy of dystonia.

Acknowledgements The authors would like to acknowledge Barbara Morelli and Raffaela Longo for their precious collaboration.
Contributors AC, RF, ET, MIP were involved in the conception and design, data acquisition, data analysis and interpretation, drafting, critical revision and supervision.

Competing interests None declared.

\section{Patient consent Obtained.}

Provenance and peer review Not commissioned; externally peer reviewed.

\section{REFERENCES}

1 Albanese A, Bhatia K, Bresssman SB, et al. Phenomenology and classification of dystonia: a consensus update. Mov Disord 2013;28: 863-73.

2 Phukan J, Albanese A, Gasser T, et al. Primary dystonia and dystonia-plus syndromes: clinical characteristics, diagnosis, and pathogenesis. Lancet Neurol 2011:10:1074-85.

3 Camargos S, Scholz S, Simón-Sánchez J, et al. DYT16, a novel young-onset dystonia-parkinsonism disorder: identification of a segregating mutation in the stress-response protein PRKRA. Lancet Neurol 2008;7:207-15.

4 Wallace DC, Murdock DG. Mitochondria and dystonia: the movement disorder connection? Proc Natl Acad Sci USA 1999;96:1817-19.

5 Costantini A, Pala Ml, Grossi E, et al. Long-term treatment with high-dose thiamine in Parkinson disease: an Open-Label Pilot Study. J Altern Complement Med 2015;21:740-7.

6 Lonsdale D. Thiamine and magnesium deficiencies: keys to disease. Med Hypotheses 2015;84:129-34.

7 Mkrtchyan G, Aleshin V, Parkhomenko Y, et al. Molecular mechanisms of the non-coenzyme action of thiamine in brain: biochemical, structural and pathway analysis. Sci Rep 2015:5:12583.

8 Butterworth RF. Thiamin deficiency and brain disorders. Nutr Res Rev 2003:16:277-84

9 Quadri M, Olgiati S, Sensi M, et al. PRKRA mutation causing early-onset generalized Dystonia-Parkinsonism (DYT16) in an Italian family. Mov Disord 2016;31:765-7.

10 Comella CL, Leurgans S, Wuu J, et al. Rating scales for dystonia: a multicenter assessment. Mov Disord 2003;18:303-12.

11 Brown G. Defects of thiamine transport and metabolism. J Inherit Metab Dis 2014;37:577-85

12 Serrano M, Rebollo M, Depienne C, et al. Reversible generalized dystonia and encephalopathy from thiamine transporter 2 deficiency. Mov Disord 2012;27:1295-8.

13 Fauci S, Braunwald E, Kasper DL, et al. Harrison's principles of Internal Medicine. 17th edn. New York: Mc Graw-Hill, 1999.

14 Ortigoza-Escobar JD, Serrano M, Molero M, et al. Thiamine transporter-2 deficiency: outcome and treatment monitoring. Orphanet J Rare Dis 2014:9:92.

15 van Dangen S, Brown RM, Brown GK, et al. Thiamine-responsive and non-responsive patients with PDHC-E1 deficiency: retrospective assessment. JIMD Rep 2015;15:13-27.

16 Thompson VB, Jinnah HA, Hess EJ. Convergent mechanisms in etiologically-diverse dystonias. Expert Opin Ther Targets 2011;15:1387-403.

17 Smithline HA, Donnino M, Greenblatt DJ. Pharmacokinetics of high-dose oral thiamine hydrochloride in healthy subjects. BMC Clin Pharmacol 2012;12:4.

Copyright 2016 BMJ Publishing Group. All rights reserved. For permission to reuse any of this content visit

http://group.bmj.com/group/rights-licensing/permissions.

BMJ Case Report Fellows may re-use this article for personal use and teaching without any further permission.

Become a Fellow of BMJ Case Reports today and you can:

- Submit as many cases as you like

- Enjoy fast sympathetic peer review and rapid publication of accepted articles

- Access all the published articles

- Re-use any of the published material for personal use and teaching without further permission

For information on Institutional Fellowships contact consortiasales@bmjgroup.com

Visit casereports.bmj.com for more articles like this and to become a Fellow 